\title{
Management of Open Tibial Shaft Fractures in Children with Intramedullary Elastic Nail
}

\section{Amr Mohamed Eladawy ${ }^{1}$, Riad Mansour Megahed ${ }^{1}$,} Abobaker Emrehil Mohamed Yosef*2, Mohamed Ibrahim Salama ${ }^{1}$

${ }^{1}$ Orthopedic Department, Faculty of Medicine, Zagazeg University, Egypt.

${ }^{2}$ Orthopedic Department, Faculty of Medicine, Tripoli University, Libya.

*Corresponding Author: Abobaker Emrehil Mohamed, Mobile: (+20)01013506461, E-mail: abobaker.m.yosef@gmail.com

\begin{abstract}
Background: Elastic intramedullary nailing is a method of diaphyseal fracture osteosynthesis in children. This technique has many advantages. Namely, there is primary bone union with avoidance of growth plate injury, early weight bearing, and minimally invasive surgery with a short duration of hospitalization. Objective: In this study, we evaluated radiological and functional results of treatment of open tibial shaft fractures in children using intramedullary elastic nail. Patients and Methods: This study was a prospective clinical study that included 24 cases with open tibial fractures treated with intramedullary elastic nail at Zagazig University Hospital (ZUH), Egypt and in Tripoli Central Hospital in Libya from June 2020 until September 2020 with six months follow-up. All patients were assessed radiologically by anteroposterior and lateral plain radiographs of the tibia that included the knee and ankle to limit unnecessary radiation. Results: The majority of studied group were excellent in 19 cases clinically according to Ketenjian and Shelton Criteria and 23 cases were united using radiological assessment. Only two cases had superficial skin infection and just one case had delayed union. Conclusion: Flexible intramedullary nailing is an effective treatment option in patients with open fracture (gustilo type I, II), four to fifteen years age group.
\end{abstract}

Keywords: Elastic Nail, Fracture, Open Tibial

\section{INTRODUCTION}

Pediatric tibial fractures are the most common fractures in children, which account for $25-43 \%$ of all childhood fractures. The annual incidence of childhood fracture varies greatly across studies from about 12 fractures per 1000 children to 36.1 fractures per 1000 children with different factors suggested to impact the incidence including geographic location, age, and gender of the patient ${ }^{(\mathbf{1})}$.

Most of the tibial shaft fractures are managed conservatively. The indications for the operative treatment include open fractures, neurovascular deficits, polytrauma, unstable fracture patterns, and fractures that fail to meet acceptable reduction parameters (roughly 10 degrees of sagittal angulation, 10 degrees of varus/valgus, $>50 \%$ translation $^{(2)}$.

Pediatric patients with high-energy tibial shaft fractures represent a challenging subset of injuries for the orthopedic surgeon. Preservation of the proximal tibial physis precludes the use of reamed, locked intramedullary nails as in the skeletally mature population, necessitating the use of other modalities. External fixation has been used to stabilize these injuries but has been shown to have increased time to union, malunion, leg-length discrepancy, pin-tract infection, and decreased functional outcome ${ }^{(3)}$.

Other fixation techniques like plate have limited utilization due to more extended dissection which leads to soft-tissue damage. Moreover, some authors suggested that applying plate under the age of twelve stimulates growth which may result in leg length discrepancy ${ }^{(\mathbf{4})}$.
Elastic intramedullary nailing is a method of diaphyseal fracture osteosynthesis in children ${ }^{(5)}$. This technique has many advantages. Namely, there is primary bone union with avoidance of growth plate injury, early weight bearing, and minimally invasive surgery with a short duration of hospitalization ${ }^{(6)}$.

This study aimed to evaluate management of open tibial shaft fractures in children with intramedullary elastic nail.

\section{PATIENTS AND METHODS}

A prospective clinical study was conducted on 24 patients (18 males and 6 females) age varied from 4 years to 15 years with a mean age \pm SD of $(9.63 \pm 1.88)$ years with fracture shaft of open tibial fractures treated with intramedullary elastic nail at Zagazig University Hospital (ZUH), Egypt and in Tripoli Central Hospital in Libya from June 2020 until September 2020 with six months follow-up.

\section{Ethical approval:}

An approval of the study was obtained from Zagazeg University academic and ethical committee. Every patient signed an informed written consent for acceptance of the operation.

\section{Inclusion criteria:}

Displaced open tibial fractures, Gustilo Anderson classification grade 1 and 2 . The fracture pattern was classified using the classification of the AO/ASIF 
(Association for Osteosynthesis/Association for the Study of Internal Fixation).

Exclusion criteria: Patients with neuromuscular disorders, skeletal dysplasia, and/or metabolic disease affecting the bone, pathological fractures, infected wounds. Medical co-morbidities such as liver disease, and chronic renal disease or unfit for surgery.

\section{Preoperative:}

All patients were subjected to history taking. All patients in the study were classified according to the Gustilo-Anderson classification including 21 cases were (G1) and 3 cases were (G2); and AO classification including 10 cases were (42A1), 8 cases were (42A2), 5 cases were (42A3) and 1 case was (42B2). All patients were assessed radiologically by anteroposterior and lateral plain radiographs of the tibia that included the knee and ankle to limit unnecessary radiation. All patients were put in above knee splint when admitted in emergency department to relieve pain and decrease soft tissue edema and prevent further soft tissue damage. All patients had full preoperative lab done before surgery including; complete blood picture, PT, PTT and INR, random blood sugar, liver and Kidney function tests.

\section{Surgical technique:}

The operation was carried out under general anesthesia using a tourniquet and complete aseptic conditions. The patient was positioned in a supine position on a radiolucent table. An image intensifier was positioned so that it can be rotated to obtain anteroposterior and lateral views of the whole tibia from the knee to the ankle joint. The entire leg including the knee and the ankle joints was prepared as an operative field. External manipulation was conducted until adequate reduction was obtained and confirmed by fluoroscopy. The diameter of the individual nail was chosen by calculation (nail diameter $=$ minimum canal diameter $\mathrm{x} 0.4$ ). To avoid varus or valgus angulation, both nails were always of identical diameter. Each nail was pre-bent at the same point by hand, ensuring that the tip lies in the same plane as the plane formed by bending, and that the apex of curvature lies at the level of the fracture site. In order to achieve optimum reduction, stabilization and alignment of the fracture, the curvature had to be identical in both nails. A $2 \mathrm{~cm}$ skin incision proximal to the required bone entry hole was made. Starting either on the anterolateral or anteromedial side of the tibia.

Regarding the entry point, the following precautions were taken into consideration; the entry point should be $2-4 \mathrm{~cm}$ distal to the proximal tibial physics. The anterolateral and anteromedial entry points should be at the same level. The entry hole should be slightly larger than the diameter of the chosen nail.

The holes were performed by a bone awl. It was directed diagonally at an angle of $45^{\circ}$ towards the far cortex to make the hole accommodating the direction of progressing nail. In six cases the holes were performed by 3.2 drill bits by applying a careful angulation movement of the drill bit until the entry hole was at an angle of at least $45^{\circ}$ (Fig. 1).
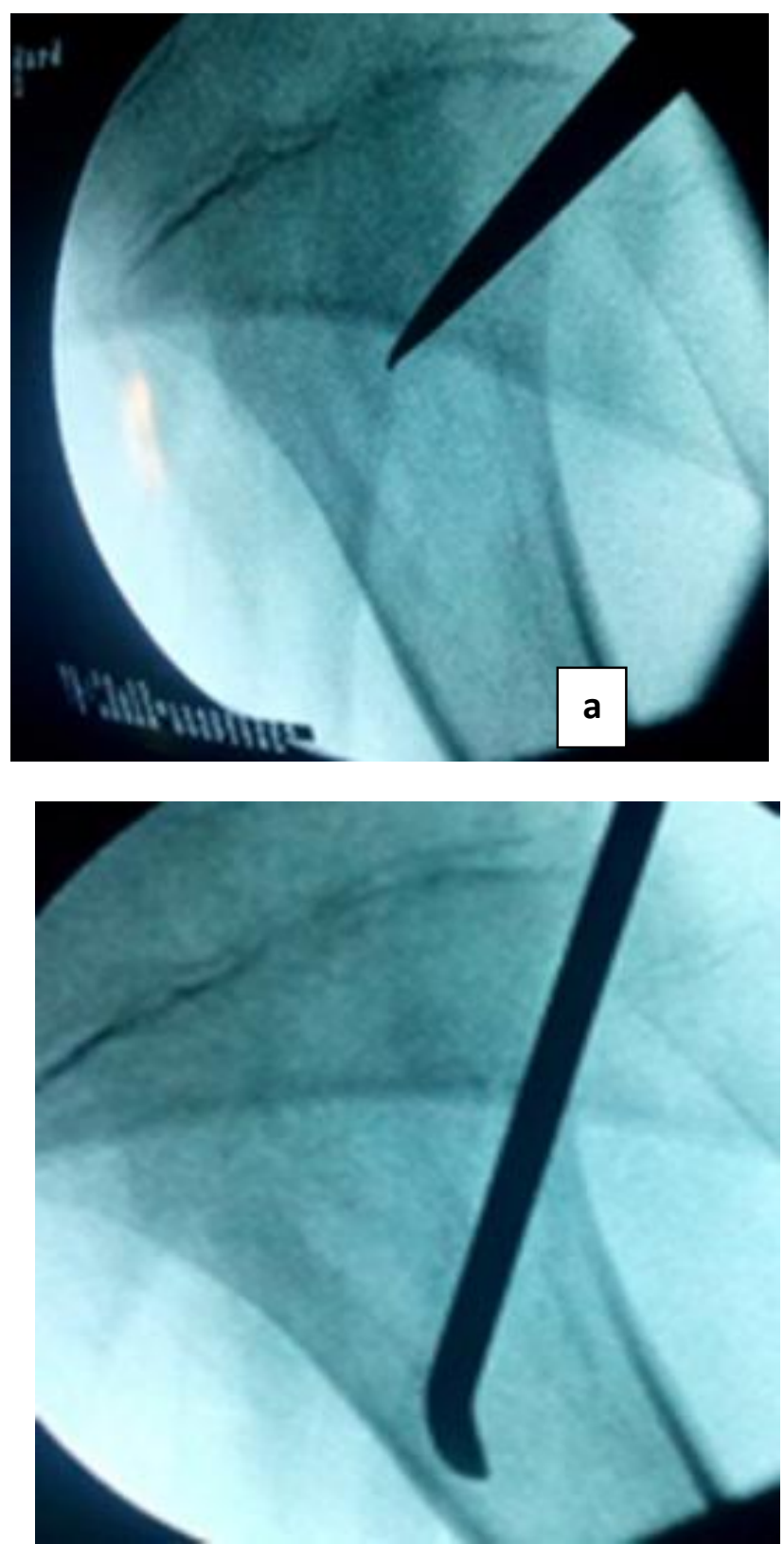

Figure (1): Entry hole and first nail

The nail was held on a cannulated $\mathrm{T}$ - handle with the horizontal bar of the T-handle and the curved tip of the nail aligned in the same plane (this allowed identification of the curved tip as it passed along the medullary canal). The nail was passed through the entry hole with the curved tip pointing downwards. The nail was driven down the canal by rotating the $\mathrm{T}$-handle back and forth. With a mallet, the nail was gently 
tapped to cross the fracture site. The nail was advanced towards the metaphysis to anchor into the cancellous bone (Fig. 2).

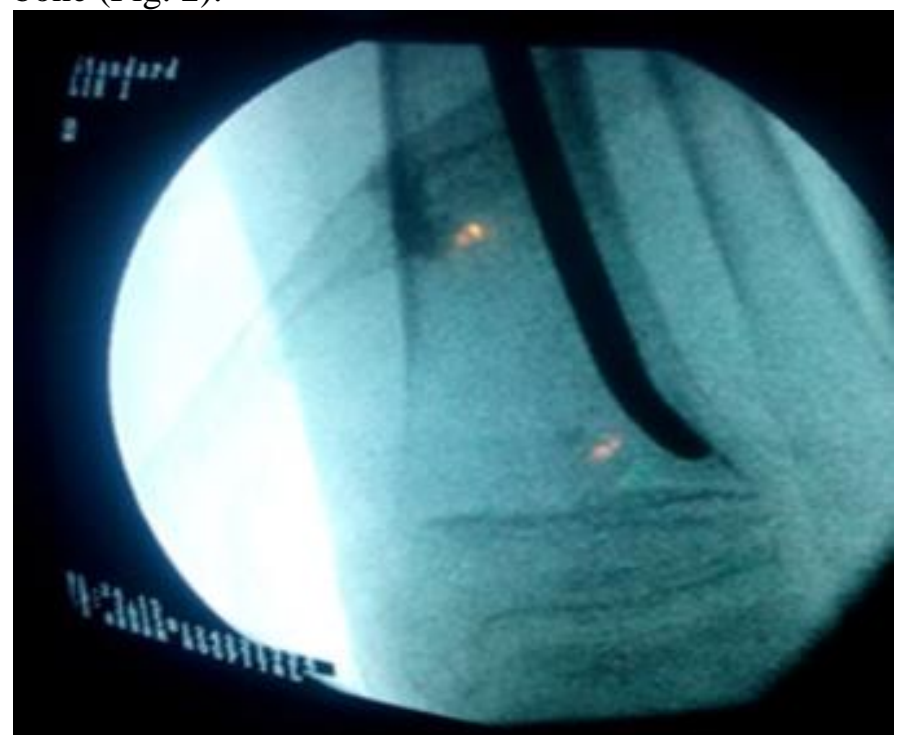

Figure (2): The first nail advanced distally

The second nail was advanced using the same rotating movements and light taps. Both nails were advanced and impacted at their final distal points just proximal to the distal tibial epiphyseal plate (Fig. 3).

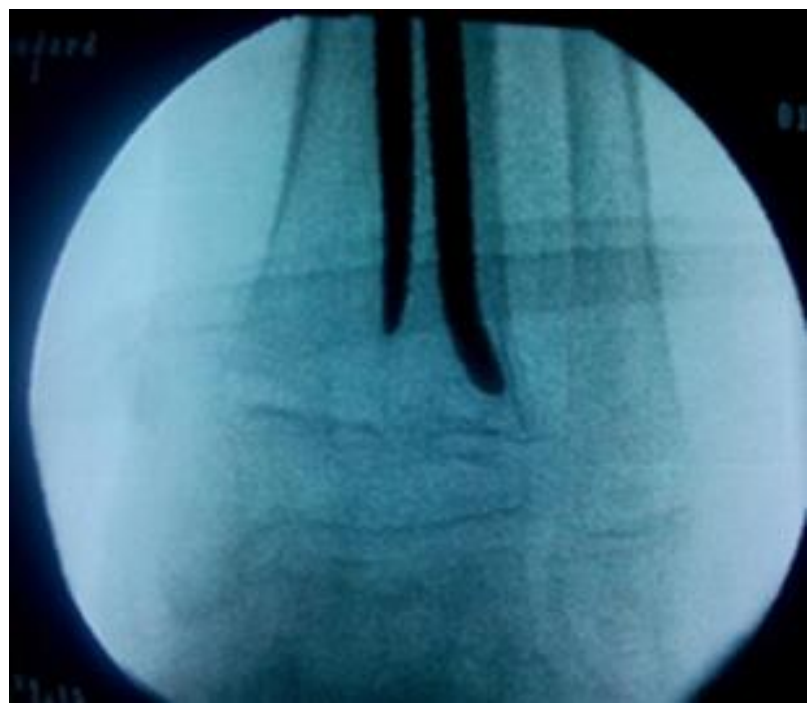

Figure (3): The second nail.

Reduction of the fracture and nail position were confirmed with the image intensifier. If the fracture was distracted, compression on the fracture was done by impacting on the patient heel. The ends of both nails were cut, ensuring that about $1 \mathrm{~cm}$ of each nail remains outside the entry hole. Wound irrigation and closure was performed in layers. Sterile dressing and above knee plaster cast was applied.

\section{Postoperative care:}

The stitches were removed after two weeks. Postoperative $\mathrm{X}$ ray was done for all patients immediately postoperatively then every 2 weeks until union then every 3 months until removal of the implant. Walking cast and partial weight-bearing with support was allowed when the fracture was pain-free and bridging callus was evident radiologically. According to fracture healing and as soon as the patient felt ready, full weight bearing was allowed (Fractures were determined to be healed with evidence of tricortical callus and no tenderness at the fracture site on clinical examination).

\section{Statistical analysis}

The collected data were coded, processed and analyzed using the SPSS (Statistical Package for Social Sciences) version 22 for Windows ${ }^{\circledR}$ (IBM SPSS Inc, Chicago, IL, USA). Data were tested for normal distribution using the Shapiro Walk test.

Qualitative data were represented as frequencies and relative percentages. Chi square test $\left(\chi^{2}\right)$ to calculate difference between two or more groups of qualitative variables. Quantitative data were expressed as mean \pm SD (Standard deviation). Independent samples t-test was used to compare between two independent groups of normally distributed variables (parametric data). $\mathrm{P}$ value $<0.05$ was considered significant.

\section{RESULTS}

14 cases had right tibial fracture $(58.3 \%)$, while 10 cases had left tibial fracture $(41.7 \%)$. The mechanism of injury 16 cases were RTA (66.7\%), 5 cases were sport injury (20.8\%) and 3 cases were fall down stairs $(12.5 \%)$ (Table 1$)$.

Table (1): Distribution of the studied patients according to side affected and mechanism of injury

\begin{tabular}{|c|c|c|c|}
\hline \multirow{3}{*}{ Side } & Left & N & \% \\
\cline { 2 - 4 } & Right & 10 & 41.7 \\
\hline \multirow{4}{*}{$\begin{array}{c}\text { Mechanism } \\
\text { of injury }\end{array}$} & Fall down stairs & 3 & 58.3 \\
\cline { 2 - 4 } & Sport injury & 5 & 20.5 \\
\cline { 2 - 4 } & $\begin{array}{c}\text { Road traffic } \\
\text { accident (RTA) }\end{array}$ & 16 & 66.7 \\
\cline { 2 - 4 } & Total & 24 & 100.0 \\
\hline
\end{tabular}

Nineteen patients were excellent regarding clinical assessment and twenty three patients had united outcome as regard radiological assessment (Table 2). 
Table (2): Clinical outcome according Ketenjian, Shelton criteria and radiological outcome distribution among studied group

\begin{tabular}{||c|c|c|c|}
\hline \multicolumn{2}{|c|}{} & $\mathrm{N}$ & $\%$ \\
\hline Clinical & Excellent & 19 & $\mathbf{7 9 . 2}$ \\
\cline { 2 - 4 } $\begin{array}{c}\text { assessment by } \\
\text { Ketenjian } \\
\text { and Shelton } \\
\text { Criteria }\end{array}$ & Good & 3 & 12.5 \\
\cline { 2 - 4 } & Fair & 2 & 8.3 \\
\hline \multicolumn{2}{|c|}{} & & \\
\hline Radiological \\
assessment & United & No. & $\%$ \\
\cline { 2 - 4 } & $\begin{array}{c}\text { Delayed } \\
\text { union }\end{array}$ & 1 & $\mathbf{9 5 . 8}$ \\
\hline
\end{tabular}

Eight patients $(33.3 \%)$ were united in $(\leq 9$ weeks) in contrast to 16 patients $(66.7 \%)$ were united in ( $\geq 9$ weeks) (Table 3 ).

Table (3): Statistical analysis of the studied patients according to time of union $(n=24)$

\begin{tabular}{|c|c|c|}
\hline Time of union (week) & No. & \% \\
\hline$\leq 9$ & 8 & 33.3 \\
$>9$ & 16 & 66.7 \\
\hline Min. - Max. & \multicolumn{2}{|c|}{$7.0-17.0$} \\
Mean \pm SD. & \multicolumn{2}{|c|}{$8.90 \pm 1.29$} \\
Median & \multicolumn{2}{|c|}{9.0} \\
\hline
\end{tabular}

There was no statistically significant relation between the time before surgery and the final score (Table 4).

Table (4): Relation between score and time before surgery (days)

\begin{tabular}{|c|c|c|c|c|}
\hline & \multicolumn{3}{|c|}{ Score } & \multirow[b]{2}{*}{$\mathbf{p}$} \\
\hline $\begin{array}{c}\text { Time before } \\
\text { surgery } \\
\text { (days) }\end{array}$ & $\begin{array}{c}\text { Fair } \\
(n=2)\end{array}$ & $\begin{array}{l}\text { Good } \\
(n=3)\end{array}$ & $\begin{array}{l}\text { Excellent } \\
(\mathbf{n}=19)\end{array}$ & \\
\hline Min. - Max. & $\begin{array}{c}1.00- \\
7.0\end{array}$ & $\begin{array}{c}2.00- \\
7.0\end{array}$ & $\begin{array}{l}1.0- \\
8.0\end{array}$ & \multirow{3}{*}{0.928} \\
\hline Mean \pm SD. & $\begin{array}{c}4.00 \pm \\
2.00 \\
\end{array}$ & $\begin{array}{c}4.00 \pm \\
2.00 \\
\end{array}$ & $\begin{array}{c}3.00 \pm \\
2.00 \\
\end{array}$ & \\
\hline Median & 2.0 & 3.00 & 2.0 & \\
\hline $\mathbf{r}_{\mathrm{s}}(\mathbf{p})$ & \multicolumn{3}{|c|}{$0.05(0.931)$} & \\
\hline
\end{tabular}

Z: Mann Whitney test , $\mathrm{r}_{\mathrm{s}}$ : Spearman coefficient

Only three cases had complication (Table 5).

Table 5: Complication distribution among studied group

\begin{tabular}{||c|c|c|c||}
\hline \multicolumn{1}{|c|}{} & $\mathrm{N}$ & $\%$ \\
\hline \multirow{3}{*}{ Complication } & No & 21 & 87.5 \\
\cline { 2 - 4 } & $\begin{array}{c}\text { Superficial } \\
\text { infection }\end{array}$ & 2 & 8.3 \\
\cline { 2 - 4 } & $\begin{array}{c}\text { Delay } \\
\text { union }\end{array}$ & 1 & 4.2 \\
\cline { 2 - 4 } & Total & 24 & 100.0 \\
\hline
\end{tabular}

\section{DISCUSSION}

In this study, there were 18 males and 6 females with a male predominance. The most common mode of injury involved was road traffic accidents (RTA) in 16 cases $(66.7 \%)$, sport injury in 5 cases (20.8\%), fall down stairs in 3 cases (12.5\%). RTA is the most common mode of injury. There is a rise in motor vehicles on the road and improper regulation of traffic rules. Because of poor socioeconomic status in this region, working parents are not able to keep an eye on their children, which lead to high road traffic $\operatorname{accidents}^{(7)}$.

The characteristics of patients of our study are consistent with Gavaskar and Singh ${ }^{(7)}$ according the age, sex, mode of injury, side affected, time for union, and range of motion at adjacent joints. The main side affected was right side; 14 right side affected $(58.3 \%)$, and 10 left side affected (41.7\%). This finding was matching with Ligier et al. ${ }^{(8)}$. The mean time of radiological union was ten weeks $10.79 \pm 1.1$ weeks, out of 24 cases this result agreed Vallamshetla et al. (9).

In this study of 24 cases, showed excellent results in $91.7 \%$ all grade I and grade II fractures and good results in $8.3 \%$. This agreed with Johnson and Davlin ${ }^{(10)}$. O'Brien et al. reported 16 fractures of the tibia, fixed internally with flexible elastic intramedullary nails, which achieved a very good functional outcome with no significant angulation or leg length discrepancy and no infections ${ }^{(\mathbf{1 1})}$. Vallamshetla et al. ${ }^{\left({ }^{9}\right)}$ reported on 56 fractures of the tibia, fixed internally with intramedullary elastic nails, with excellent outcome in $84 \%$ of cases (two residual angulations of the tibia, two leg-length discrepancy, two deep infections, one delayed union and two failures of fixation).

In this series, the mean time to union was 8.90 \pm 1.29 weeks, which was comparable to other studies using the same method of fixation. The mean time to radiological union in Gordon et al. ${ }^{(12)}$ work was 8 weeks (range from four to eighteen weeks). In Vallamshetla et $\boldsymbol{a l} .{ }^{\left({ }^{(9)}\right.}$ work it was 10 weeks (range from seven to eighteen weeks), and in Sankar et al. ${ }^{\left({ }^{(13)}\right.}$ the mean time to union was 11 weeks (range 6-18 weeks), with closed fractures healing more rapidly than open fractures. Our results were also similar to those of Qidwai $^{(\mathbf{1 4})}$ who reported a mean time to union of 9.4 weeks in a study of eighty-four tibial fractures (including thirty open fractures) in children (mean age, 10.2 years) who had been managed with Kirschner wires that had been placed in the same fashion as described for the flexible intramedullary nails in the present study. Srivastava et al. ${ }^{(15)}$ reported a longer time to union than the other studies at 20.7 weeks (range 8-42 weeks). However, union was described as "painless full weight bearing with radiographic 
evidence of tricortical callous formation". This is in contrast to the other studies that solely considered radiographic union.

Most common complication seen in our study was superficial infection and delay union that have minimal incidence (12.5\%). This agreed with Pandya and Edmonds ${ }^{(16)}$.

In this series all fractures united. This was comparable to results reported in other studies using elastic stable intramedullary nailing (ESIN) as reported

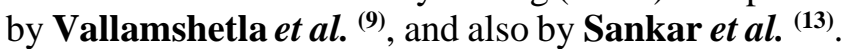
However; Srivastava et al. ${ }^{(15)}$ reported two non-united cases and Gordon et al. ${ }^{(\mathbf{1 2})}$ reported also two cases of non-union.

\section{CONCLUSION}

Flexible intramedullary nailing is an effective treatment option in patients with open fracture (gustilo type I, II), four to fifteen years age group. The procedure has low morbidity and good results with short hospitalization. Most of the associated complications can be avoided by strictly adhering to the basic principles and technical aspects.

\section{REFERENCES}

1. Wolfe J, Wolfe H, Banaag A et al. (2019): Early pediatric fractures in a universally insured population within the United States. BMC Pediatr., 19(1):1-6.

2. Ganesan R, Anbu S, Palaniappan M et al. (2016): Elastic stable intramedullary nailing of femoral and tibial shaft fractures in children. J Evol Med Dent Sci., 5(71):5196-201.

3. Alberghina F, Andreacchio A, Cravino $M$ et al. (2019): Extra-articular proximal femur fractures in children and adolescents treated by elastic stable intramedullary nailing. Int Orthop., 43(12):2849-56.

4. Burkus M, Tömböl F, Wiegand $\mathrm{N}$ et al. (2020): Physeal-sparing unreamed locked intramedullary nailing for adolescent tibial fractures. Injury, 2020: 1-7.

5. Kim P, Leopold S (2019): Erratum to: In brief: GustiloAnderson classification. Clin Orthop Relat Res., 477(10):2388.

6. Mashru R, Herman M, Pizzutillo P (2005): Tibial shaft fractures in children and adolescents. JAAOSJournal Am Acad Orthop Surg., 13(5):345-52.

7. Gavaskar B, Singh R (2020): Management of diaphyseal long bone fractures in paediatric age group by tens. Int J Orthop., 6(1):460-3.

8. Ligier J, Metaizeau J, Prévot J et al. (1998): Elastic stable intramedullary nailing of tibial shaft fractures in children. J Bone Joint Surg Br., 70(1):74-7.

9. Vallamshetla V, De Silva U, Bache $\mathrm{C}$ et al. (2006): Flexible intramedullary nails for unstable fractures of the tibia in children: An eight-year experience. J Bone Joint Surg Br., 88(4):536-40.

10. Johnson E, Davlin L (1993): The indications for immediate open reduction and internal fixation. Clinical Orthopaedics and Related Research, 292:118-127.

11. O'Brien T, Weisman D, Ronchetti $P$ et al. (2004): Flexible titanium nailing for the treatment of the unstable pediatric tibial fracture. J Pediatr Orthop., 24(6):601-9.

12. Gordon J, Gregush R, Schoenecker $P$ et al. (2007): Complications after titanium elastic nailing of pediatric tibial fractures. Journal of Pediatric Orthopaedics, 27(4):442-6.

13. Sankar W, Jones K, David Horn B et al. (2007): Titanium elastic nails for pediatric tibial shaft fractures. J Child Orthop., 1:281-286.

14. Qidwai S (2001): Intramedullary Kirschner wiring for tibia fractures in children. J Pediatr Orthop., 21(3): 2947.

15. Srivastava A, Mehlman C, Wall E et al. (2008): Elastic stable intramedullary nailing of tibial shaft fractures in children. J Pediatr Orthop., 28(2):152-158.

16. Pandya N, Edmonds $E$ (2012): Immediate intramedullary flexible nailing of open pediatric tibial shaft fractures. J Pediatr Orthop., 32 (8): 770-6. 